\title{
Immunogenicity of Peptide-vaccine Candidates Predicted by Molecular Dynamics Simulations
}

\author{
Clasien J. Oomen ${ }^{1,2}$, Peter Hoogerhout ${ }^{2}$, Alexandre M.J.J. Bonvin ${ }^{3}$ \\ Betsy Kuipers ${ }^{2}$, Humphrey Brugghe ${ }^{2}$, Hans Timmermans ${ }^{2}$ \\ Simon R. Haseley ${ }^{4}$, Loek van Alphen ${ }^{2}$ and Piet Gros ${ }^{1 *}$
}

\author{
${ }^{1}$ Department of Crystal and \\ Structural Chemistry, Bijvoet \\ Center for Biomolecular \\ Research, Utrecht University \\ Padualaan 8, NL-3584 CH \\ Utrecht, The Netherlands
}

${ }^{2}$ Netherlands Vaccine Institute (NVI), P.O. Box 457, NL-3720

AL Bilthoven, The Netherlands

${ }^{3}$ Department of

NMR-spectroscopy, Bijvoet

Center for Biomolecular

Research, Utrecht University

Padualaan 8, NL-3584 CH

Utrecht, The Netherlands

${ }^{4}$ Department of Bio-Organic

Chemistry, Bijvoet Center for

Biomolecular Research, Utrecht

University, Padualaan 8

NL-3584 CH, Utrecht, The

Netherlands

\begin{abstract}
We present an in silico, structure-based approach for design and evaluation of conformationally restricted peptide-vaccines. In particular, we designed four cyclic peptides of ten or 11 residues mimicking the crystallographically observed $\beta$-turn conformation of a predicted immunodominant loop of PorA from Neisseria meningitidis. Conformational correctness and stability of the peptide designs, as evaluated by molecular dynamics simulations, correctly predicted the immunogenicity of the peptides. We observed a peptide-induced functional antibody response that, remarkably, exceeded the response induced by the native protein in outer membrane vesicles, without losing specificity for related strains. The presented approach offers tools for a priori design and selection of peptide-vaccine candidates with full biological activity. This approach could be widely applicable: to outer membrane proteins of Gram-negative bacteria, and to other epitopes in a large range of pathogens.
\end{abstract}

(C) 2003 Elsevier Science Ltd. All rights reserved
Keywords: peptide-vaccine; molecular dynamics; structure-based design; immunogenicity; beta-turn
Peptides may have potential to afford safe, noninfective, well-defined and stable vaccines. However, induction of functional humoral immunity with unstructured peptide vaccines may be difficult. Even if the protein epitope comprises a continuous amino acid sequence, peptides containing this sequence may induce antibodies that lack cross-reactivity with the parent protein or whole microorganism. Molecular mimicry to the cognate antigen seems to be required for inducing a functional, cross-reactive immune response. ${ }^{1}$ In several studies this functional molecular mimicry has been achieved by a trial-and-error approach, ${ }^{2-7}$ by

Abbreviations used: Lys-SAMA, $N^{\varepsilon}$-(S-acetylmercaptoacetyl)lysine; OMV, outer membrane vesicle.

E-mail address of the corresponding author: p.gros@chem.uu.nl combinatorial chemistry display techniques ${ }^{8,9}$ or by structure-based design. ${ }^{10-12}$ Similar to approaches in structure-based drug design, crystal or solution structures of peptide-antibody complexes are often used to optimize the complementarity between a peptide and a functional antibody, which should thus lead to higher binding affinity. ${ }^{13}$ However, it is not the binding to an antibody that is important for the design of immunogenic peptides, but rather the molecular mimicry of the unbound peptide to the cognate antigen. ${ }^{14}$ This cannot be optimized by modeling a peptide into an antibody structure, but rather by investigating the conformational properties of the peptide. ${ }^{10,11}$ Irrespective of the method used for obtaining the designs, peptide-vaccine candidates have to be tested to validate their competence in vivo. ${ }^{14}$ However, prediction of the conformational 
(a)

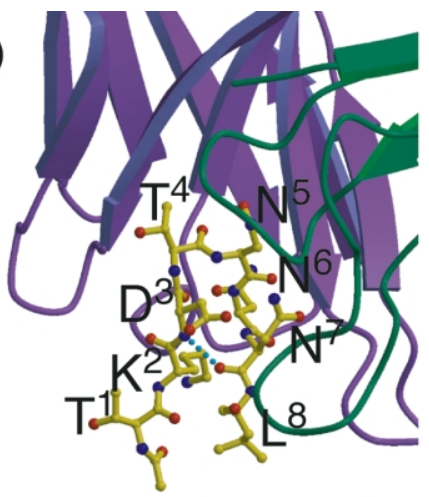

(c)

A
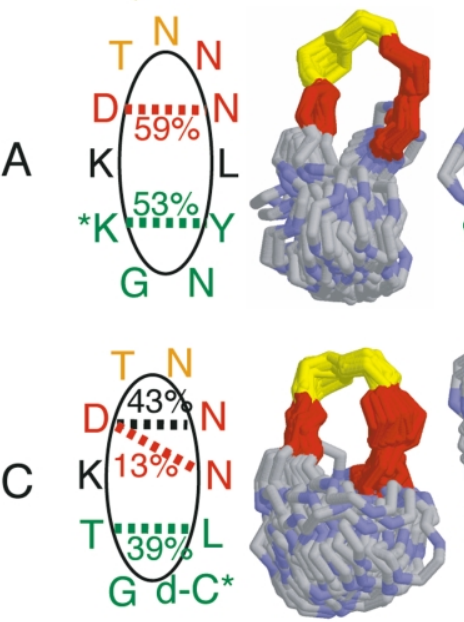
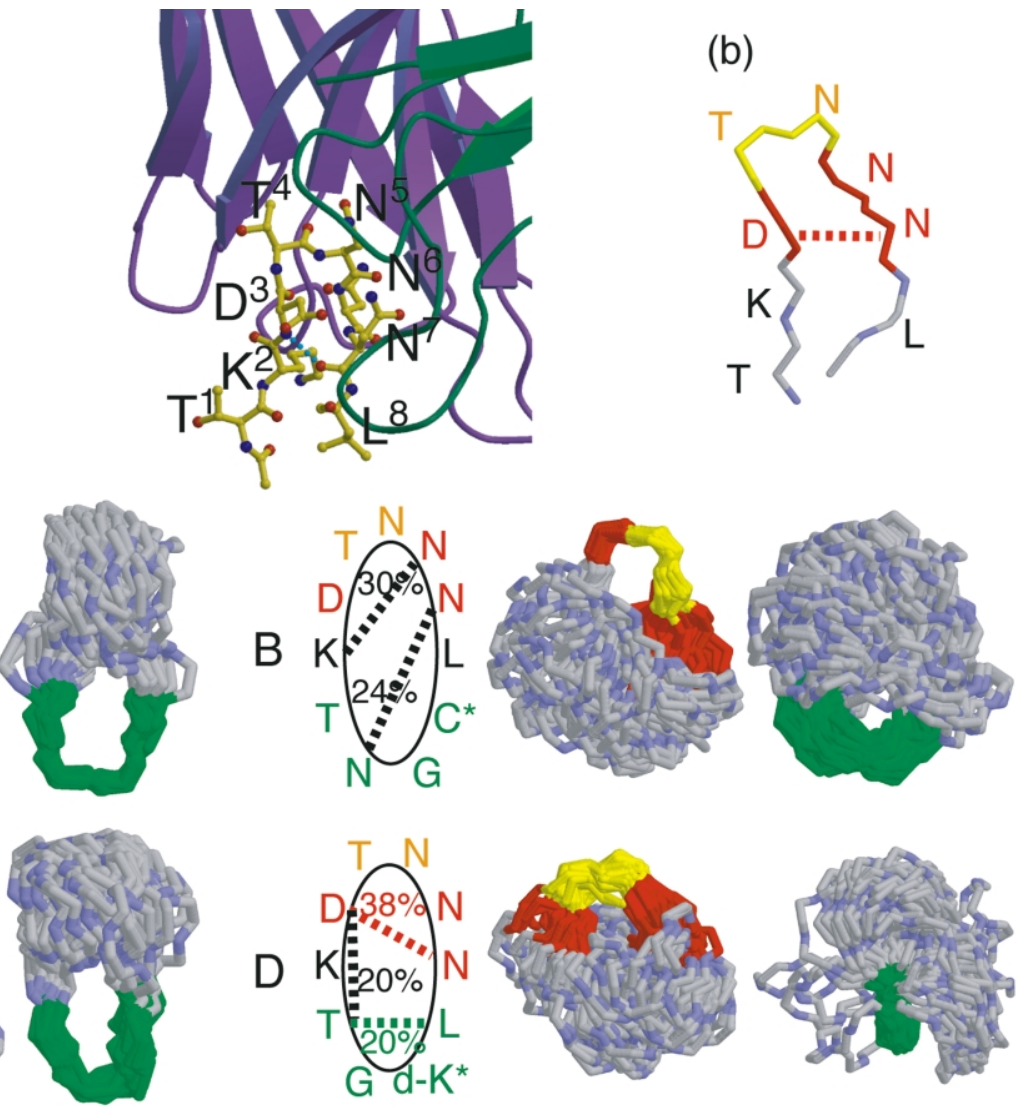

(b)

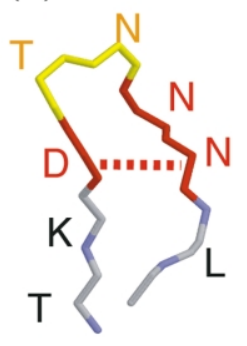

$\mathrm{D}$
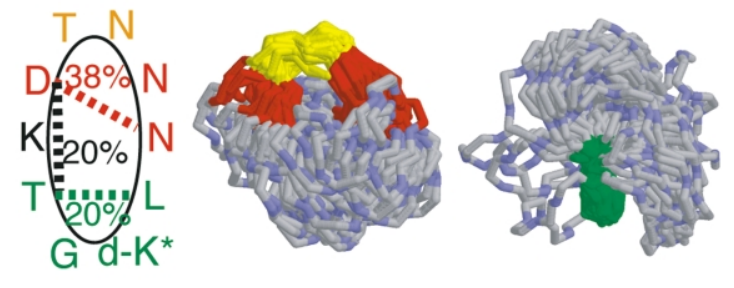

Figure 1. Target conformation, in silico evaluation of peptide designs. (a) Stereo view and (b) backbone conformation of the linear epitope peptide showing a 3:5 type I $\beta$-turn at residues ${ }^{\mathrm{P} 3} \mathrm{DTNNN}^{\mathrm{P7}}$ (corresponding to residues $182-186$ in PorA), as observed in complex with a Fab fragment from a bactericidal antibody against N. meningitidis subtype P1.16 in a crystal structure. ${ }^{17}$ Peptide-vaccine candidates were designed to mimic this conformation; designs are represented schematically using the one-letter code for amino acids in (c); asterisks indicate the site for attachment to carrier protein tetanus toxoid. To reduce the flexibility, the peptides were conformationally restricted by head-to-tail cyclization. The residues of the contra-turn were chosen to have a high propensity to form a $\beta$-turn, thus stabilizing the epitopeturn conformation by prolonging the hydrogen-bonding network. Molecular dynamics simulations of the peptides were done to assess the conformational mimicry of the peptides to the crystallographically observed $\beta$-turn. (c) Snapshots of the peptides during the molecular dynamics simulation run were superimposed on either epitope-turn (red and yellow) or contra-turn (green). The conformational mimicry is assessed by the presence in the simulation of the desired backbone (red and green dotted lines) and undesired (black dotted lines) hydrogen bonds; the percentages of simulation time for observed hydrogen bond formation are included in the representation of the designs. For the molecular dynamics simulations, the molecular models of the peptide designs were constructed with the desired contraturn and energy minimized using InsightII (version 98, Accelrys Inc.). The conformational properties of the cyclic peptides were investigated by molecular dynamics using the GROMOS96 package. ${ }^{31}$ The simulations were run under NPT conditions in explicit solvent for $10 \mathrm{~ns}$ at $400 \mathrm{~K}$ as described. ${ }^{32}$ Simulations were analyzed by GROMOS96 analyzing programs, using common hydrogen-bond restrictions (donor-acceptor distance $\leq 2.5 \AA$, donor-hydrogen-acceptor angle $\geq 135^{\circ}$ ).

properties of the peptides could a priori select the most promising peptide designs for further in vivo testing.

Outer-membrane proteins display $\beta$-barrel structures with generally extended loops at the bacterial surface. These surface-exposed loops may be immunogenic and are often observed to form $\beta$-turn structures. ${ }^{15}$ One example in Neisseria meningitidis is the abundant outer-membrane protein porin PorA, which is predicted to contain eight surface-exposed loops. ${ }^{16}$ Most variability between PorA protein of different subtypes resides in three variable regions, VR1, VR2 and, less pronounced, VR3, which correspond to the predicted loops 1, 4 and 5, respectively. ${ }^{16}$ Monoclonal antibodies reacting with peptide epitopes located on loops 1, 4 (and 5) have been found to be bactericidal. This makes these epitopes good candidates for the development of subtype-specific peptide vaccines.

The PorA P1.16 subtype investigated in this study is a common subtype, which is located on loop 4. For this subtype, immunogenic, cyclic peptides of 15-35 amino acid residues have been discovered by empirical research. ${ }^{5,6}$ The crystal structure of a Fab fragment from a bactericidal antibody specific for this subtype in complex with a linear peptide $\left({ }^{\mathrm{P} 1} \mathrm{TKDTNNNL}{ }^{\mathrm{P} 8}\right.$, corresponding 
to residues $180-187$ in PorA $)^{17}$ has given opportunities for structure-based improvement of the peptide designs. Computational lead-optimization of the peptide using LUDI, however, did not yield peptides with higher binding affinities, ${ }^{13}$ nor were these peptides tested for their immunogenicity. Though our approach is based on the same crystal structure, it does not optimize binding, but rather optimizes the molecular mimicry of the hairpin with a 3:5 type I $\beta$-turn at residues DTNNN ( $a: b$ nomenclature as used by Sibanda et $a l .{ }^{18}$ (Figure 1(a)). The peptide designs were conformationally restricted by head-to-tail cyclization and evaluated in silico by molecular dynamics simulations and in vivo by an immunization experiment in mice. Additionally, the affinities of the peptides for two bactericidal antibodies were measured.

\section{Peptide design}

We chose head-to-tail cyclization of the peptides to stabilize the crystallographically observed $\beta$-hairpin conformation. ${ }^{17}$ Residues for cyclization were selected to have a high propensity to form a second $\beta$-turn, the contra-turn, prolonging the hydrogen bonding network ${ }^{19-22}$ and hence stabilizing the $\beta$-turn of the epitope. A reverse turn conformation was chosen, because it provides the appropriate geometry, topological twist and in-register peptide alignment. ${ }^{23}$ In addition, a high immune response requires conjugation to a carrier protein, for which we used tetanus toxoid. Thus, a site for conjugation was incorporated in the contra-turn either by a cysteine or by an $N^{\varepsilon}$-(S-acetylmercaptoacetyl)lysine residue (Lys-SAMA), both of which can be attached to a sulfhydryl-reactive protein

Peptides A and B consisted of 11 residues (Figure 1(c)). The contra-turn of peptide A was designed to form a type $\mathrm{I}^{\prime} \beta$-turn using the most commonly observed residues for this turn, ${ }^{19,24}$ i.e. Tyr-Asn-Gly-Lys for position $i$ to $i+3$. The turnstabilizing properties of asparagine and glycine are supported by experimental studies and molecular dynamics unfolding studies. ${ }^{19,24-27}$ Unlike the contra-turn of peptide $\mathrm{A}$, the contra-turn of peptide $\mathrm{B}$ was designed to form a type $\mathrm{II}^{\prime}$ turn with residues Cys-Gly-Asn-Tyr. The type $\mathrm{II}^{\prime}$ turn conformation is stabilized by the asparagine residue at position $i+2$, which has a preference for adopting the $\phi, \psi$ conformation characteristic for this turn $\left(\phi=80^{\circ}, \psi=0^{\circ}\right) .^{19}$ Though a tyrosine residue at position $i$ is preferred in this turn, a cysteine residue was chosen to introduce a site for conjugation.

Peptides C and D consisted of only ten residues (Figure 1(c)). D-Cysteine and D-lysine-SAMA were chosen for position $i+1$ of peptides $C$ and $D$, because D-amino acids are known to stabilize a reverse turn by favoring positive $\phi$ angles. ${ }^{28} \mathrm{~A}$ glycine residue was chosen for position $i+2$, as this amino acid can adopt the correct $\phi, \psi$-angles $\left(90^{\circ}\right.$, $0^{\circ}$ for type $\mathrm{I}^{\prime}$ and $-80^{\circ}, 0^{\circ}$ for type $\mathrm{II}^{\prime}$ ). In order to have a higher overlap in sequences of peptide and protein, the amino acid residues at positions $i$ and $i+3$ were chosen to be the same as in the cognate protein, i.e. leucine and threonine respectively. These amino acid residues form a common pair in anti-parallel $\beta$-sheets ${ }^{20}$ and are not uncommon in reverse turns. ${ }^{19}$

\section{Assessment of peptide designs by molecular dynamics simulation}

Molecular dynamics simulations of the four designed P1.16 peptides were performed to assess the conformational stability of the desired $\beta$-turn in silico (Figure 1(c)). In these simulations, the presence of the hydrogen bond between mainchain $\mathrm{Asp}^{\mathrm{P3}} \mathrm{NH}$ and $\mathrm{Asn}^{\mathrm{P7}} \mathrm{CO}$ was used as a criterion to assess the stability of the 3:5 type I $\beta$-turn. In peptide $A$, the designed 3:5 type I $\beta$-turn epitope conformation was observed for $58 \%$ of the time. Concomitantly, its contra-turn yielded a relatively stable type $\mathrm{I}^{\prime} \beta$-turn present for $53 \%$ of the simulation time. These data were supported by solution NMR experiments, showing that the peptide was very flexible (chemical shifts close to random coil, no long-range nuclear Overhauser effects (NOEs)), but with medium-range NOEs that were in agreement with the presence of the epitope- and contra-turn (data not shown). In contrast, the epitope-turn conformation in peptide $\mathrm{B}$ was shifted by one residue, yielding a 2:4 turn for KDTN present $30 \%$ of the time. Overall, peptide B was highly flexible and no stable conformation was observed for the contra-turn. In peptide $C$, the desired 3:5 DTNNN turn conformation was observed for only $13 \%$ of the time. Instead, the dominant conformation of the epitope-turn was a $2: 4$ DTNN turn present for $43 \%$ of the time; the contra-turn was found to be relatively stable in a type $I^{\prime} \beta 2: 4$ conformation present $39 \%$ of the time. Finally, peptide D was highly flexible with no stable contra-turn conformation, but still displayed a correct 3:5 DTNNN turn for $38 \%$ of the simulation time. In summary, the simulations indicated that: (1) peptide A displayed the correct conformation for $58 \%$ of the simulation and was the least-flexible peptide design; (2) peptide D displayed the correct conformation of the epitope turn for $38 \%$ of the simulation, but remained very flexible; (3) peptides B and C were predominantly in an incorrect conformation for the epitope. Therefore, in silico evaluation of the peptide designs put peptide A forward as the best potential vaccine candidate followed by peptides D, C and B.

\section{Evaluation of peptide design by SPR- binding studies}

An SPR-binding assay was used to determine the affinity of the designed peptides for two bactericidal antibodies. We observed large differences in binding affinity for the four peptides, in the 


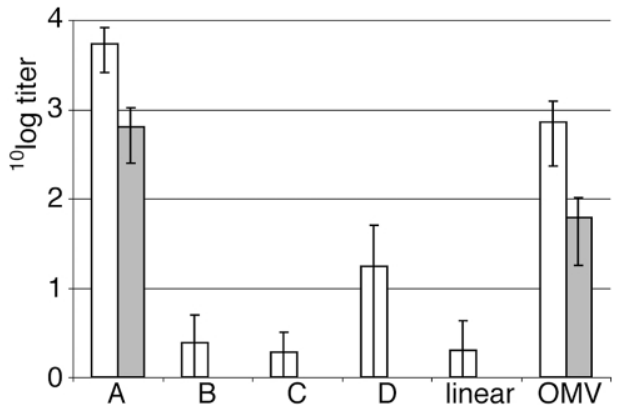

Figure 2. In vitro and in vivo evaluation of the peptide designs $\mathrm{A}$ to $\mathrm{D}$ and a linear control peptide. Binding to bacteria in whole-cell ELISA (open bars) and complement activation in a bactericidal assay (filled bars) of sera from immunization experiments in mice of the peptides conjugated to tetanus toxoid, and outer membrane vesicles (OMV), used as a positive control. Bactericidal antibodies were induced only by peptide-A conjugate and OMV, with highest titers for peptide-A conjugate, (both exceed the antibody response observed after natural infection). The immunization experiments, wholecell ELISA experiments and serum bactericidal assays were performed as described, ${ }^{6}$ using groups of minimally five BALB/c mice (20-24 g) per peptide conjugate. Unless stated otherwise, the vaccine contained $50 \mu \mathrm{g}$ of peptide conjugate and $20 \mu \mathrm{g}$ of Quillaja saponin A (Quil A) per mouse. Peptides were synthesized and purified as described, ${ }^{6}$ and analyzed by HPLC/ion spray ionization mass spectrometry. For immunization, the peptides were coupled to bromoacetylated tetanus toxoid to give thioether conjugates, as described. ${ }^{6}$ Additional binding experiments of the cyclic peptides $\mathrm{A}-\mathrm{D}$ and the linear control peptide (Ac-YTKDTNNNLTL-NH ${ }_{2}$ ) to a bactericidal antibody were performed using surface plasmon resonance. The BIAcore 2000 apparatus, CM5 sensor chip, HBS-EP buffer and amino coupling kit were obtained from Pharmacia Biosensor AB (Uppsala, Sweden). The anti-P1.16 antibodies $\mathrm{MN} 12 \mathrm{H} 2^{17}$ and MN5C11G ${ }^{33}$ were coupled to the chip by standard amine coupling according to the manufacturer's instructions. ${ }^{34}$ Different concentrations of peptides, ranging from $16 \mathrm{nM}$ to $100 \mu \mathrm{M}$ in HBS-EP buffer, were flowed across the surface at a rate of $5 \mu \mathrm{l} /$ minute. Results were analyzed by BIAevaluation software 3.0 using a standard 1:1 Langmuir binding model, where appropriate with drifting baseline, and yielded $K_{\mathrm{D}}$ values for MN5C11G of: A, $16 \mathrm{nM}\left(\chi^{2}=0.63\right) ; B, 32 \mathrm{nM}$ $\left(\chi^{2}=0.62\right) ; \mathrm{C}, 500 \mu \mathrm{M}\left(\chi^{2}=0.36\right) ; \mathrm{D} 110 \mu \mathrm{M}\left(\chi^{2}=0.61\right)$; and linear $57 \mathrm{nM} \quad\left(\chi^{2}=0.56\right) ;$ and $K_{\mathrm{D}}$ values for MN12H2 of: A, $19 \mathrm{nM}\left(\chi^{2}=0.48\right)$; B $0.59 \mu \mathrm{M}\left(\chi^{2}=0.29\right)$; C, $7.3 \mu \mathrm{M}\left(\chi^{2}=0.18\right) ; \mathrm{D}, 5.1 \mu \mathrm{M}\left(\chi^{2}=0.11\right)$; and linear $0.96 \mu \mathrm{M}\left(\chi^{2}=0.11\right)$. NMR experiments included standard nuclear Overhauser effect spectroscopy (mixing time $400 \mathrm{~ms}$ ) and total correlated spectroscopy experiments (mixing time $80 \mathrm{~ms}$ ) at $278 \mathrm{~K}$ using a sample containing approximately $0.2 \mathrm{mM}$ peptide $\mathrm{A}$ in a $20 \mathrm{mM}$ sodium phosphate buffer at $\mathrm{pH} 5.5$ and $10 \%{ }^{2} \mathrm{H}_{2} \mathrm{O}$ on a Bruker AMX $600 \mathrm{MHz}$ spectrometer.

order of decreasing affinity $\mathrm{A}>\mathrm{B}>$ linear peptide $\gg \mathrm{D}>\mathrm{C}$ for both antibodies (with $K_{\mathrm{D}}$ values for antibody MN5C11G of $16 \mathrm{nM}, 32 \mathrm{nM}, 57 \mathrm{nM}$, $110 \mu \mathrm{M}$ and $500 \mu \mathrm{M}$, respectively, and of $19 \mathrm{nM}$, $0.59 \mu \mathrm{M}, 1.0 \mu \mathrm{M}, 5.1 \mu \mathrm{M}$ and $7.3 \mu \mathrm{M}$, respectively, for antibody MN12H2 with $\chi^{2}$ values between 0.1
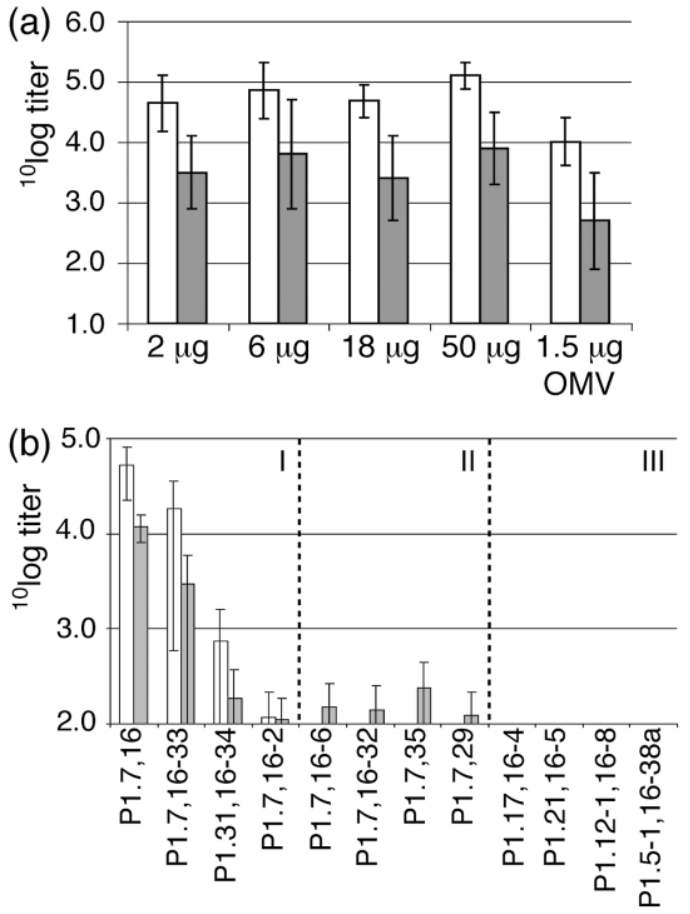

Figure 3. Immunological properties of peptide-A conjugate: (a) Binding to bacteria (open bars) and bactericidal activity (filled bars) of sera induced by different doses of peptide-A conjugate, ranging from $2 \mu \mathrm{g}$ to $50 \mu \mathrm{g}$, and by $1 / 10$ human dose of OMV. Comparable titers were elicited by all doses of peptide conjugate $(p=0.37)$ and all peptide-induced titers were higher than the titers elicited by outer membrane vesicles (OMV) $(p<0.01)$. (b) Titers induced by the lowest dose of peptide-A conjugate (open bars) and OMV (filled bars) were analyzed for their cross-reactivity in wholecell ELISA using different strains. The strains were obtained from the Netherlands Reference Laboratory for Bacterial Meningitis (AMC/RIVM) and from the RIVM collection; the sequence of loop 4 (VR2), the loop 1 (VR1) and the reactivity with monoclonal anti-P1.16 antibody MN5C11G are shown in Table 1. Subtypes are named as in the N.meningitidis PorA Variable Region Database. Based on the recognition by the peptide- and OMV-induced sera, strains were categorized in: (I) strains fully recognized by either of the sera: full crossreactivity concerning the P1.16 epitope, (II) strains lowly recognized by OMV sera, but not by peptide sera; the cross-reactivity of the OMV-induced sera most likely comes from the P1.7 epitope as present in the P1.7,16 OMV, (III) strains which were not recognized by either of the sera: no cross-reactivity of the sera with the P1.16 variants.

and 0.6 when fit with a standard 1:1 Langmuir model).

\section{Immunization trials}

Immunization experiments in mice were performed for the four cyclic peptides $\mathrm{A}-\mathrm{D}$ and a linear control peptide with sequence Ac-KDTNN NLYNG-(Lys-SAMA)- $\mathrm{NH}_{2}$ conjugated to tetanus toxoid. As a positive control outer membrane vesicles (OMV), consisting for $90 \%$ of PorA 
Table 1. Strains and loop 4 sequences used in cross-reactivity experiments

\begin{tabular}{|c|c|c|c|c|c|c|c|}
\hline Strain & $\begin{array}{l}\text { Sero- } \\
\text { group }\end{array}$ & $\begin{array}{l}\text { Sero- } \\
\text { type }\end{array}$ & $\begin{array}{l}\text { Loop } 1 \\
\text { sequence } \\
\text { subtype }^{\text {a }}\end{array}$ & $\begin{array}{l}\text { Loop } 4 \\
\text { sequence } \\
\text { subtype }^{\text {a }}\end{array}$ & Sequence loop $4^{\text {b }}$ & $\begin{array}{l}\text { Reaction with } \\
\text { Mab anti-P1.16 }\end{array}$ & Category $^{\mathrm{d}}$ \\
\hline $\mathrm{H} 44 / 76$ & B & 15 & P1.7 & P1.16 & YYTKDTNNNLTLVP & + & I \\
\hline 2000119 & B & 15 & P1.7 & P1.16-33 & YYTNTKDTNNNLTLVP & + & I \\
\hline 2000644 & B & 4 & P1.31 & P1.16-34 & YYTKDTNNNLKDTNNNLTLVP & + & I \\
\hline MC58 & B & 15 & P1.7 & P1.16-2 & YYTKNTNNNLTLVP & $+1-$ & I \\
\hline 00260 & B & 15 & P1.7 & P1.16-6 & YYTKHTNNNLTLVP & - & II \\
\hline 2000024 & B & 15 & P1.7 & P1.16-32 & YYTKVTNNNLTLVP & - & II \\
\hline 2001411 & B & 15 & P1.7 & P1.16-35 & YYTKHANNNLTLVP & - & II \\
\hline 10402 & $\mathrm{C}$ & 15 & P1.7 & P1.16-29 & YYTKGTNNDLTLVP & $-1+$ & II \\
\hline 10904 & B & $\mathrm{Nt}$ & P1.17 & P1.16-4 & YYTKDKNDKLTLVP & - & III \\
\hline 00298 & B & $\mathrm{Nt}$ & P1.21 & P1.16-5 & YYTKDTNNNNNLTLVP & - & III \\
\hline 2010550 & B & 4 & P1.12-1 & P1.16-8 & YYTKDKNNALTLVP & - & III \\
\hline 00151 & $\mathrm{C}$ & $\mathrm{Nt}$ & P1.5-1 & P1.16-38a $\dagger$ & YYAKDTNNNLTLVP & - & III \\
\hline
\end{tabular}

${ }^{\text {a }}$ Loop 1 and 4 sequence subtypes named as in the N. meningitidis PorA Variable Region Database (http://neisseria.org); subtype P1.16-38a has not been included in the database.

b The changes in sequence to the P1.16 subtype are designated in bold.

${ }^{\mathrm{c}}$ Reaction with anti-P1.16 monoclonal antibody MN5C11G measured in this study, conducted as described. ${ }^{6}$

d Based on the recognition by the peptide-A conjugate and OMV-induced sera, strains were categorized in: (I) strains fully recognized by either of the sera: full cross-reactivity concerning the P1.16 epitope; (II) strains little recognized by OMV sera, but not by peptide sera; the cross-reactivity of the OMV-induced sera most likely comes from the P1.7 epitope as present in the P1.7,16 OMV; (III) strains that were not recognized by either of the sera: no cross-reactivity of the sera with the P1.16 variants.

subtype P1.7,16, were included in the experiment. ${ }^{29}$ Peptide conjugates A and D, and OMV elicited antibodies that bound whole bacteria (Figure 2). However, only peptide A and the OMV elicited bactericidal antibodies, which activated the complement system and induced killing of the bacteria in vitro. In the absence of a good animal model for meningococcal disease, the serum bactericidal activity assay is considered a good predictor for the protection against N. meningitidis serogroup B. ${ }^{30}$ Remarkably, the bactericidal titers induced by peptide-A conjugate were higher than the titers induced by the OMV $(p<0.01)$.

Subsequently, immunizations were performed using different doses of peptide-A conjugate, ranging from $2 \mu \mathrm{g}$ to $50 \mu \mathrm{g}$, where $50 \mu \mathrm{g}$ of conjugate is the standard dose used in immunization experiments. ${ }^{6}$ The obtained sera were compared to the sera induced by $1.5 \mu \mathrm{g}$ of OMV, a 1/10 human dose that is generally used in mice experiments. These experiments revealed no dose-dependency $(p=0.37)$ and showed that all doses of peptide conjugate elicited bactericidal-antibody titers that were higher than the titer induced by OMV $(p<0.01)$ (Figure 3(a)).

The antibodies induced by the lowest dose of peptide-A conjugate or OMV were tested for their cross-reactivity with other strains in whole-cell ELISA (Table 1). We observed three categories of strains based on the recognition by the peptide-induced and OMV-induced sera (Figure 3(b)). Strains of the first category, including P1.16, P1.16-33, P1.16-34 and, to a lesser extent, P1.16-2, were recognized by both sera raised by OMV and peptide A. In addition, these strains were recognized by the anti-P1.16 monoclonal antibody used in our binding assay. These data indicated full cross-reactivity of the sera with these strains. Strains of the second category, including P.16-6, P1.16-32, P1.16-35 and P1.16-29, were recognized weakly by the sera induced by OMVs. Peptide-induced sera gave little or no reaction with these strains, indicating that the sera were not cross-reactive with these $\mathrm{P} 1.16$ variants. This is in agreement with the observation that anti-P1.16 monoclonal antibody did not recognize strains from this category. The observed cross-reactivity of the OMV-induced sera is therefore most likely due to the other epitope (P1.7) present in the OMV; this is supported by binding of anti-P1.7 monoclonal antibody to all of these strains (data not shown). Strains of the third category, P1.16$38 \mathrm{a} \dagger, \mathrm{P} 1.16-5, \mathrm{P} 1.16-4$ and P1.16-8, were not, or hardly, recognized by either of the sera, nor by anti-P1.7 and anti-P1.16 monoclonal antibodies. The OMV-induced and peptide-induced sera are not cross-reactive with these strains, indicating that P1.7 is absent and sequence and conformation of the P1.16 variants were distinct from the original epitope. In conclusion, the sera induced by peptide-A conjugate and by OMV showed same coverage of recognition of P1.16 variants.

\section{Implications for vaccine development}

In silico evaluation by molecular dynamics simulations may select peptide designs that have the highest conformational mimicry to the cognate protein, and will thus most likely be good vaccine candidates. We used peptide cyclization to reduce the flexibility of the peptide designs and restrain their conformation towards the conformation

$\dagger$ Subtype variant P1.16-38a is not registered in the PorA variable region database 
observed in a peptide-Fab complex. The reduced flexibility and structural mimicry imply that the restrained peptide has higher binding affinities for bactericidal antibodies than a similar linear peptide, due to the reduced loss of entropy upon binding. Though we observed this for the functional peptide A, the binding studies could not fully discriminate between peptide designs: also the nonfunctional peptide B had high binding affinities for both antibodies. In contrary, free molecular dynamics simulations proved to be capable of assessing the competence of the peptide designs correctly. Contrary to previous trial-and-error work on this epitope ${ }^{5,6}$ this method could select a peptide as having optimal conformational properties. This peptide A was the only peptide that induced a high, cross-reactive and bactericidal antibody titer in an immunization experiment in mice.

Interestingly, even a low dose of peptide-A conjugate- induced sera with antibody titers exceeding the titer obtained when using $1 / 10$ human dose of protein in its natural conformation (as present in the OMV). This indicated that the higher immunogenicity of the peptide was not caused by the high concentration of specific antigen, but by a different, peptide-specific mechanism, possibly due to a better accessibility of the epitope. In addition, these sera of polyclonal antibodies with enhanced bactericidal activity showed a cross-reactivity among the 12 tested strains of P1.16 variants that is identical with cross-reactivity of sera obtained by OMV immunization. These data demonstrate that good, conformational peptide vaccines may perform better than OMV-based vaccines.

The structure-based method for design and selection of peptide-vaccine candidates presented here may have a higher chance of success than empirical approaches and has the advantage that only a limited number of peptides needs to be synthesized and tested in an immunological assay. When structural data are available, it could be applied to any linear B-cell epitope of any pathogen. More specifically, the cyclization method presented here may be most suitable for mimicking surface loops of outer membrane proteins in Gram-negative bacteria, as many surface loops occur in $\beta$-turn conformations.

\section{Acknowledgements}

We thank the Netherlands Reference Laboratory for Bacterial Meningitis (AMC/RIVM) for providing us with the P1.16-variant strains. This work was supported, in part, by the Council for Chemical Sciences of the Netherlands Organization for Scientific Research (NWO-CW).

\section{References}

1. Arnon, R. \& Van Regenmortel, M. H. (1992). Struc- tural basis of antigenic specificity and design of new vaccines. FASEB J. 6, 3265-3274.

2. Langeveld, J. P. M., Casal, J. I., Osterhaus, A. D. M. E., Cortes, E., de Swart, R., Vela, C. et al. (1994). First peptide vaccine providing protection against viral infection in the target animal: studies of canine parvovirus in dogs. J. Virol. 68, 4506-4513.

3. Muller, S., Plaue, S., Samama, J. P., Valette, M., Briand, J. P. \& Van Regenmortel, M. H. V. (1990). Antigenic properties and protective capacity of a cyclic peptide corresponding to site A of influenza virus haemagglutinin. Vaccine, 8, 308-314.

4. Luo, Y., Zeng, Q., Glisson, J. R., Jackwood, M. W., Cheng, I. H. \& Wang, C. (1999). Sequence analysis of Pasteurella multocida major outer membrane protein $(\mathrm{OmpH})$ and application of synthetic peptides in vaccination of chickens against homologous strain challenge. Vaccine, 17, 821-831.

5. Christodoulides, M., McGuinness, B. T. \& Heckels, J. E. (1993). Immunization with synthetic peptides containing epitopes of the class 1 outer-membrane protein of Neisseria meningitidis: production of bactericidal antibodies on immunization with a cyclic peptide. J. Gen. Microbiol. 139, 1729-1738.

6. Hoogerhout, P., Donders, E. M., van Gaans-van den Brink, J. A., Kuipers, B., Brugghe, H. F., van Unen, L. M. et al. (1995). Conjugates of synthetic cyclic peptides elicit bactericidal antibodies against a conformational epitope on a class 1 outer membrane protein of Neisseria meningitidis. Infect. Immun. 63, 3473-3478.

7. Sundaram, R., Dakappagari, N. K. \& Kaumaya, P. T. (2002). Synthetic peptides as cancer vaccines. Biopolymers, 66, 200-216.

8. Meloen, R. H., Puijk, W. C. \& Slootstra, J. W. (2000). Mimotopes: realization of an unlikely concept. J. Mol. Recogn. 13, 352-359.

9. Craig, L., Sanschagrin, P. C., Rozek, A., Lackie, S., Kuhn, L. A. \& Scott, J. K. (1998). The role of structure in antibody cross-reactivity between peptides and folded proteins. J. Mol. Biol. 281, 183-201.

10. Ghiara, J. B., Ferguson, D. C., Satterthwait, A. C., Dyson, H. J. \& Wilson, I. A. (1997). Structure-based design of a constrained peptide mimic of the HIV-1 V3 loop neutralization site. J. Mol. Biol. 266, 31-39.

11. Cuniasse, P., Thomas, A., Smith, J. C., Thanh, H. L., Leonetti, M. \& Menez, A. (1995). Structural basis of antibody cross-reactivity: solution conformation of an immunogenic peptide fragment containing both $\mathrm{T}$ and B epitopes. Biochemistry, 34, 12782-12789.

12. Valero, M. L., Camarero, J. A., Haack, T., Mateu, M. G., Domingo, E., Giralt, E. \& Andreu, D. (2000). Native-like cyclic peptide models of a viral antigenic site: finding a balance between rigidity and flexibility. J. Mol. Recogn. 13, 5-13.

13. Fischer, M. J., Kuipers, C., Hofkes, R. P., Hofmeyer, L. J., Moret, E. E. \& de Mol, N. J. (2001). Exploring computational lead optimisation with affinity constants obtained by surface plasmon resonance for the interaction of PorA epitope peptides with antibody against Neisseria meningitidis. Biochim. Biophys. Acta, 1568, 205-215.

14. Van Regenmortel, M. H. (2001). Antigenicity and immunogenicity of synthetic peptides. Biologicals, 29, 209-213.

15. Koebnik, R., Locher, K. P. \& Van Gelder, P. (2000). Structure and function of bacterial outer membrane proteins: barrels in a nutshell. Mol. Microbiol. 37, 239-253. 
16. van der Ley, P., Heckels, J. E., Virji, M., Hoogerhout, P. \& Poolman, J. T. (1991). Topology of outer membrane porins in pathogenic Neisseria spp. Infect. Immun. 59, 2963-2971.

17. van den Elsen, J. M., Herron, J. N., Hoogerhout, P., Poolman, J. T., Boel, E., Logtenberg, T. et al. (1997). Bactericidal antibody recognition of a PorA epitope of Neisseria meningitidis: crystal structure of a Fab fragment in complex with a fluorescein-conjugated peptide. Proteins: Struct. Funct. Genet. 29, 113-125.

18. Sibanda, B. L., Blundell, T. L. \& Thornton, J. M. (1989). Conformation of beta-hairpins in protein structures. A systematic classification with applications to modelling by homology, electron density fitting and protein engineering. J. Mol. Biol. 206, 759-777.

19. Hutchinson, E. G. \& Thornton, J. M. (1994). A revised set of potentials for beta-turn formation in proteins. Protein Sci. 3, 2207-2216.

20. Hutchinson, E. G., Sessions, R. B., Thornton, J. M. \& Woolfson, D. N. (1998). Determinants of strand register in antiparallel beta-sheets of proteins. Protein Sci. 7, 2287-2300.

21. Smith, C. K. \& Regan, L. (1995). Guidelines for protein design: the energetics of beta sheet side chain interactions. Science, 270, 980-982.

22. Wouters, M. A. \& Curmi, P. M. (1995). An analysis of side chain interactions and pair correlations within antiparallel beta-sheets: the differences between backbone hydrogen- bonded and non-hydrogenbonded residue pairs. Proteins: Struct. Funct. Genet. 22, 119-131.

23. Gibbs, A. C., Bjorndahl, T. C., Hodges, R. S. \& Wishart, D. S. (2002). Probing the structural determinants of type $\mathrm{II}^{\prime}$ beta-turn formation in peptides and proteins. J. Am. Chem. Soc. 124, 1203-1213.

24. Ramirez-Alvarado, M., Kortemme, T., Blanco, F. J. \& Serrano, L. (1999). Beta-hairpin and beta-sheet formation in designed linear peptides. Bioorg. Med. Chem. 7, 93-103.

25. Ramirez-Alvarado, M., Blanco, F. J., Niemann, H. \& Serrano, L. (1997). Role of beta-turn residues in beta- hairpin formation and stability in designed peptides. J. Mol. Biol. 273, 898-912.

26. Griffiths-Jones, S. R., Maynard, A. J. \& Searle, M. S. (1999). Dissecting the stability of a beta-hairpin peptide that folds in water: NMR and molecular dynamics analysis of the beta-turn and beta-strand contributions to folding. J. Mol. Biol. 292, 1051-1069.

27. Blanco, F., Ramirez-Alvarado, M. \& Serrano, L. (1998). Formation and stability of beta-hairpin structures in polypeptides. Curr. Opin. Struct. Biol. 8, 107-111.

28. Weisshoff, H., Prasang, C., Henklein, P., Frommel, C., Zschunke, A. \& Mugge, C. (1999). Mimicry of beta II'-turns of proteins in cyclic pentapeptides with one and without D-amino acids. Eur. J. Biochem. 259, 776-788.

29. van der Ley, P., van der Biezen, J. \& Poolman, J. T. (1995). Construction of Neisseria meningitidis strains carrying multiple chromosomal copies of the porA gene for use in the production of a multivalent outer membrane vesicle vaccine. Vaccine, 13, 401-407.

30. Vermont, C. \& Van den Dobbelsteen, G. (2002). Neisseria meningitidis serogroup B: laboratory correlates of protection. FEMS Immun. Med. Microbiol. 34, 89-96.

31. Scott, W. R. P., Huenenberger, P. H., Ilario, G. T., Mark, A. E., Billeter, S. R., Fennen, J. et al. (1999). The GROMOS biomolecular simulation program package. J. Phys. Chem. ser. A, 103, 3596-3607.

32. Bonvin, A. M. \& van Gunsteren, W. F. (2000). Betahairpin stability and folding: molecular dynamics studies of the first beta-hairpin of tendamistat. J. Mol. Biol. 296, 255-268.

33. Sacchi, C. T., Lemos, A. P., Brandt, M. E., Whitney, A. M., Melles, C. E., Solari, C. A. et al. (1998). Proposed standardization of Neisseria meningitidis PorA variable-region typing nomenclature. Clin. Diagn. Lab. Immunol. 5, 845-855.

34. Anonymous, (1994). BIAapplications Handbook. Pharmacia Biosensor AB, Uppsala, Sweden.

Edited by I. Wilson

(Received 10 January 2003; received in revised form 11 March 2003; accepted 13 March 2003) 